\title{
An Aerial Study of Hawaiian Wave Patterns
}

\author{
K. O. EMERY ${ }^{1}$
}

MosT OF US who have had some experience at sea on small power or sailing boats have noted that the sea surface is crossed by usually more than a single train or set of waves. Each train can be identified by its direction, period, and height. Sometimes one train is so dominant that others may not be noticed. The Marshall Islanders of the nineteenth century and earlier, past masters in the art of handling small boats, used wave trains as a navigational aid with their famous stick charts. The dominant train of waves, produced by the trade winds, was designated by long parallel sticks tied to a rigid frame. Trains of smaller waves, some produced by bending around islands; were shown by small sticks attached at angles to the long ones. A brief review of these maps and of pertinent literature was given by Emery, Tracey, and Ladd (1954:5).

A better platform than a boat for mapping waves is an airplane because of its wider field of view and greater speed. The greater speed permits observations to be made at many points in an area during a period short enough to reduce the effect of changes in winds. The first such wave maps made by aerial observation were for the sea off southern California in 1957-58 (Emery, 1958). Each of four surveys at 3-month intervals exhibited three or four trains of waves, greatly complicating the identification of waves refracted or reflected by the island or mainland shores. In order to simplify the analysis it is necessary to study an area having only a single wave train. The Hawaiian Islands were thought to constitute such an area because they lie within the belt of trade winds, especially during summer. An opportunity for study there was provided by the convening of the Tenth Pacific Science Congress at Honolulu during the latter half of August, 1961.

${ }^{1}$ University of Southern California, Los Angeles 7, California. Now: Woods Hole Oceanographic Institution, Woods Hole, Mass.

Manuscript received January 10, 1962.
Through the interest of the Office of Naval Research, flight facilities were made available by Fleet Air Wing Two, Naval Air Station, Barbers Point, Oahu. The aircraft was a Neptune (P2V), having a bombardier station with excellent visibility. Acting as recorders and photographers during one flight were Charles G. Johnson (U.S. Geological Survey) and Charles Roberts (U.S. Weather Bureau); and during the other flight Robert S. Dietz (U.S. Navy Electronics Laboratory) and Joe S. Creager (University of Washington). Appreciation is also due Doak C. Cox (University of Hawaii) and Saul Price (U.S. Weather Bureau, Honolulu) for their critical reading of the manuscript.

\section{METHODS}

Flights were made on 31 August (1000-1700, local time) and 1 September (0800-1430). They covered a total distance of $4200 \mathrm{~km}$ at an altitude of $500 \mathrm{~m}$. A total of 375 observation points were occupied at 2-min intervals. Positions of the aircraft were based upon fixes at 10-20-min intervals using loran, radar, and visual methods.

Observation was purely visual, although some photographs were taken for illustrative purposes. A specially devised pelorus was held with the aircraft's true compass heading set on the disk in a fore-and-aft direction. Moveable arms pivoted at the center of the disk were set parallel to the crests of separate wave trains, requiring constant visual checking and readjustment. At 2-min intervals the recorder noted the azimuth indicated by each arm. Comparison of results obtained at different headings of the aircraft indicate that the azimuths are correct within $10^{\circ}$. Estimation of the azimuth of the crests of each wave train usually required viewing in a particular direction because the waves were most clearly seen when viewed away from the sun at a horizontal angle of about $45^{\circ}$ to the wave crests and at a downward angle of 15 to $45^{\circ}$. Sometimes about $10 \mathrm{sec}$ of viewing was required 
to identify the trains of smaller waves or waves of similar azimuths. This time requirement and the different optimum directions of viewing reduces the value of interpretation from photographs alone; in addition, photographs themselves must be interpreted later-a more difficult process than direct visual interpretation of the wave azimuths. Direct visual observation also permitted the determination of the direction of wave progress, relative to the positions of foam patches. Timing the interval between the appearance of a foam patch at the crests of successive waves provided an estimate of wave periods.

In addition to wave data, observations on wind direction and speed at the water surface were obtained. The wind direction was taken as the azimuth of the long narrow parallel wind slicks which appeared where wind speed exceeded Beaufort 3. Wind speed was estimated according to the Beaufort scale of water surface characteristics (Bowditch, 1943:52), as shown below.

\begin{tabular}{c|l|c}
\hline $\begin{array}{c}\text { BEAUFORT } \\
\text { NUMBER }\end{array}$ & \multicolumn{1}{|c|}{$\begin{array}{c}\text { DESCRIPTION } \\
\text { OF SEA }\end{array}$} & $\begin{array}{c}\text { SPEED } \\
\text { (KM/HR) }\end{array}$ \\
\cline { 2 - 3 } 0 & mirrorlike & $0-2$ \\
1 & wavelets & $2-6$ \\
2 & short waves & $6-12$ \\
3 & scattered whitecaps & $12-19$ \\
4 & many whitecaps & $19-30$ \\
5 & foam streaks & $30-40$ \\
\hline
\end{tabular}

The author does not apologize for not using a more modern and sophisticated technique involving elaborate camera arrangements or electronic scanning devices, because direct observation is simpler and sufficient for the problem.

\section{WINDS}

Weather maps for the period, based upon ship and shore stations as well as upon TIROS photographs, are illustrated by Figure 1 . The two high pressure areas north and northeast of Hawaii are characteristic of the season. A low pressure area about $800 \mathrm{~km}$ southeast of Hawaii discovered by TIROS satellite was mild and its effect was not detected during the flights. The isobars show that the wind in the vicinity of the Hawaiian Islands should have been from about $070^{\circ}$ (east-northeast); this is typical of the trade-wind period of the year.

A far more detailed picture of the wind pattern was provided by aerial observation (Fig. 2 ). On the windward side of the islands the wind speed was Beaufort 4 except adjacent to the island of Hawaii, whose blocking effect reduced the wind to below Beaufort 2. On the immediate leeward side of the islands the wind was reduced to Beaufort 1 by shielding effects. Between the islands the wind was sped by funnelling, so that a speed of Beaufort 5 occurred between Hawaii and Maui. A tongue of Beaufort $4+$ extended from between Oahu and Molokai to a position off the south coast of Oahu. Verification of its presence was obtained by anemometer readings aboard R/V "Argo" of Scripps Institution of Oceanography, which worked in that area during 2 September. These tongues of high wind speed expanded and joined laterally well to the lee of Maui. However, still farther to the southwest is an area of winds less than Beaufort 3 having an unknown extent. Possibly this area is the result of the combined lees of all the islands; if so, it would be of interest to learn how much farther southwestward the area extends.

Wind direction was estimated from slicks which were long (to $500 \mathrm{~m}$ ), narrow (a few meters), and occurred in parallel series ( $5-50$ $\mathrm{m}$ apart) parallel to the wind. These wind slicks are zones of convergence between cells of surface water caused to rotate around horizontal axes by the wind (Woodcock, 1944). Oil (perhaps from phytoplankton) collects in the convergences and changes the light reflectivity and wave pattern, as observed by Dietz LaFond (1950). Other debris, including sugar mill wastes, were locally present in some slicks. The wind slicks were restricted to areas having wind speeds of Beaufort 3 or more, and are one of many phenomena which are dependent upon this critical wind speed (Munk, 1947). As shown by Figure 2 the windflow lines, deduced from the wind slicks, spread apart to pass around the islands, particularly around large and high Hawaii. Their concentration in the straits causes the high wind speeds there.

In areas having wind of less than Beaufort 3, wind slicks were usually absent. In the lee of Hawaii and Maui their place was taken by slicks 


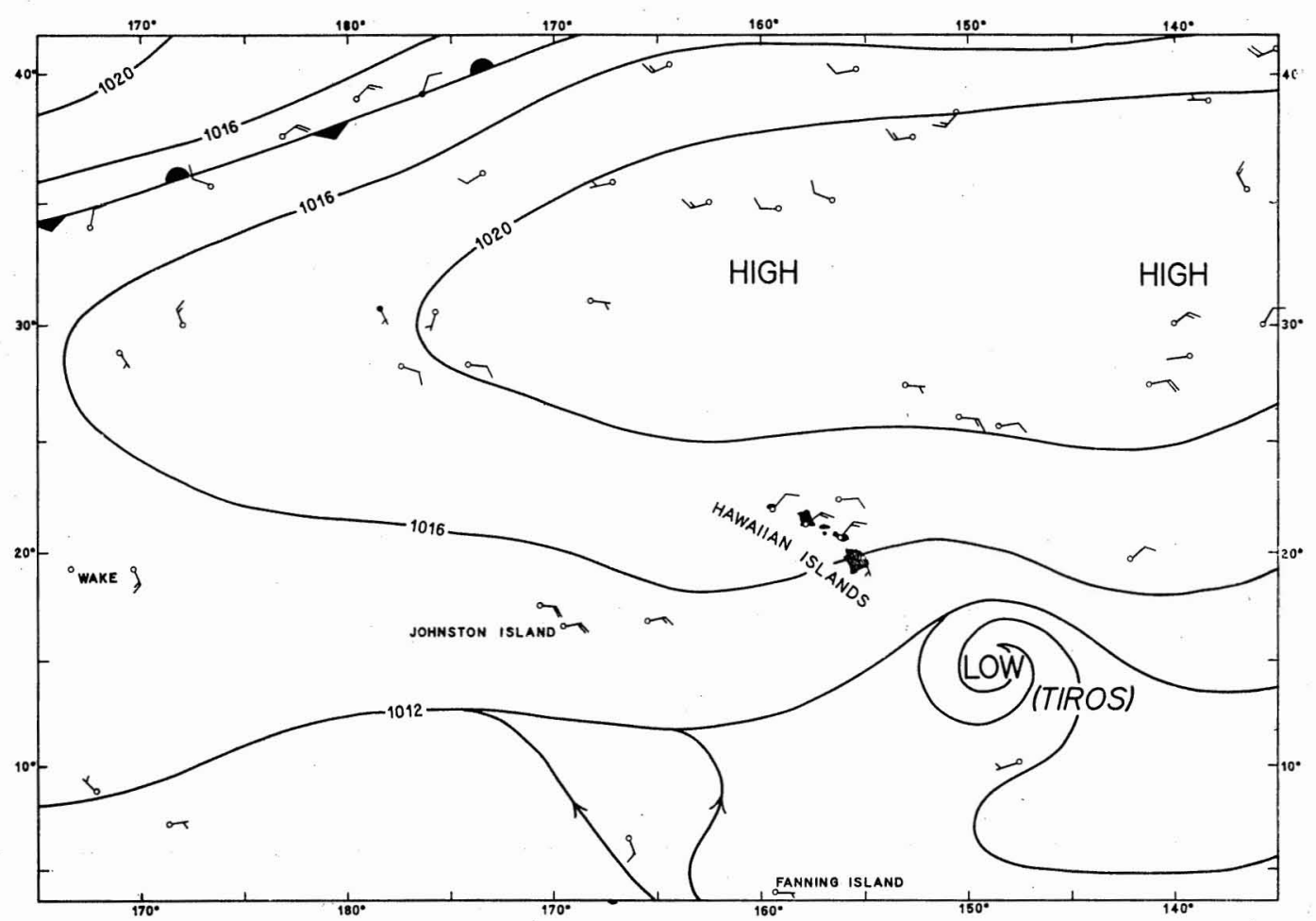

FIG. 1. Weather map for 1600 Honolulu time (0600 G.C.T.) on 31 August 1961. The winds and isobars are typical of the season for the Hawaiian Islands, except for the minor low to the southeast. Courtesy of Charles Roberts of Honolulu office of U. S. Weather Bureau.

of another kind, ones which are commonly several $\mathrm{km}$ long, 20-200 m wide, broadly sinuous, and 1 or more $\mathrm{km}$ apart. Their general trend happened to be more or less perpendicular to the wind and parallel to shore. These slicks are typical of convergences above shallow internal waves (Ewing, 1950; LaFond, 1959). A third kind of slick was noted behind a ship-straight, parallel-sided, about $30 \mathrm{~m}$ wide, and oily brown. It clearly resulted from ship wastes, probably from pumping of bilges or fuel tanks.

\section{WAVES}

Instead of the anticipated single train of waves, the area was found to contain three trains of large long-period waves and several trains of small short-period ones. Many measurements of the former waves revealed an average of 7 -sec period, whereas the latter were $1 \mathrm{sec}$ or shorter. Most of the wave energy was confined to the two trains of 7 -sec waves coming from the east $\left(090^{\circ}\right)$ and southeast $\left(130^{\circ}\right)$. The train from the east was slightly sharper crested, perpendicular to the wind slicks (compare Figs. 2 and 3 ), and most frequently topped by whitecaps. Interference between these two trains caused the sea surface to be broken into a diamond-shaped pattern, each block of which contained a short section of wave crest.

Along the sides of the islands, wave refraction caused the waves to bend and to approach parallelism with shore, but the width of the zone was generally too small to map on the scale of the survey. At the straits the waves took a circular front, evidently due to diffraction (Arthur, 1951). The shapes of the wave fronts are similar to those of the tsunamis studied by Shepard, Macdonald, and Cox (1950) in the Hawaiian region, but the latter are controlled more by refraction than by diffraction owing to their great wave length. Spreading of the circular 
fronts beyond the straits partially filled the area leeward of the islands. Locally, complex interference patterns resulted from crossing of wave trains from different straits. In general, however, the leeward sides of the islands had only low waves of the 7-sec period. Southwest of Oahu a third train of 7-sec waves was observed moving northward; it is of unknown origin.

The waves of about 1 -sec period were too short to have been produced by other than local winds. However, their round crests and large angle with the wind slicks indicate that these waves were not being formed during the time of the survey. Possibly the ones northeast of the island chain and southeast of Hawaii remained from a local wind which blew just prior to the survey; these areas were surveyed only during 31 August. The waves southwest of the chain were more irregular in pattern and may have owed their origin to cold air masses flowing down the slopes of several islands.

\section{EFFECTS ON SHORES}

During a study of beachrock in the Hawaiian Islands by Emery and Cox (1956) the shores of most of the islands were examined in detail. Others were viewed from the air during the wave survey. These shores can be classified as follows: rocky (irregular and commonly rugged, with sea cliffs and only narrow beaches or pocket beaches), sandy (long, broad sand beaches), and muddy (mangroves, narrow beaches or none, locally with lagoons or artificial fish ponds). Ignoring transitional forms, the shore types of the islands are illustrated by Figure 4 . A relationship of the shore type to the chief wave pattern, that from a generally easterly direction, can readily be observed. High storm waves from any direction (Arthur, 1948) also can control the shore types, but infrequency of the storms and inconstancy in direction of their waves reduces their importance.

Rocky shores characterize the sides of the islands most exposed to direct wave attack, except at Kaneohe Bay (east side of Oahu) where a wide offshore reef protects the shore. In some areas, such as almost the entire circumference of Hawaii, rocky shores dominate, regardless of exposure direction, probably because of the recency of volcanism. Longshore currents developed by a diagonal approach of waves to the shore have caused much of the sediment produced by wave attack of the rocky shores or of adjoining reefs to be carried beyond the areas of greatest exposure to waves. Some of

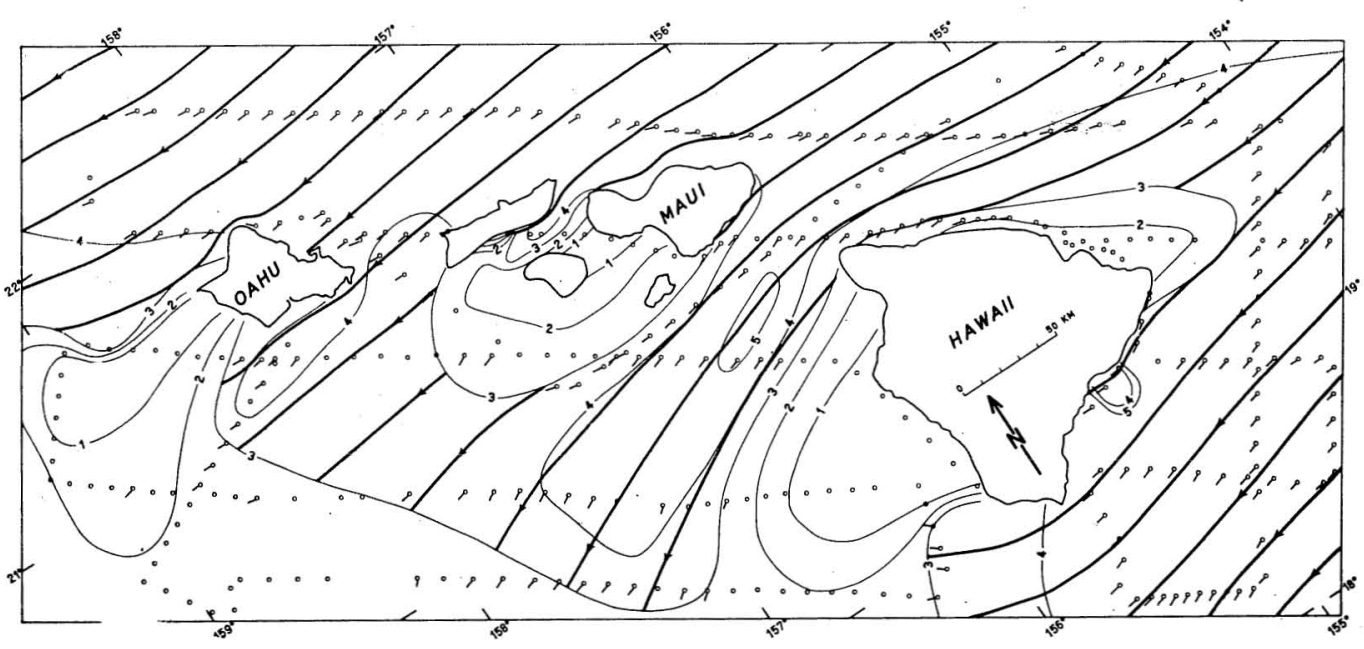

FIG. 2. Results of aerial observation of wind at sea surface on 31 August and 1 September 1961 . Wind flow lines (wide lines) are based upon wind slicks observed at each position (note weather-vane line at each position). Wind speeds are based upon condition of sea surface expressed in Beaufort scale (indicated by narrow numbered lines). 


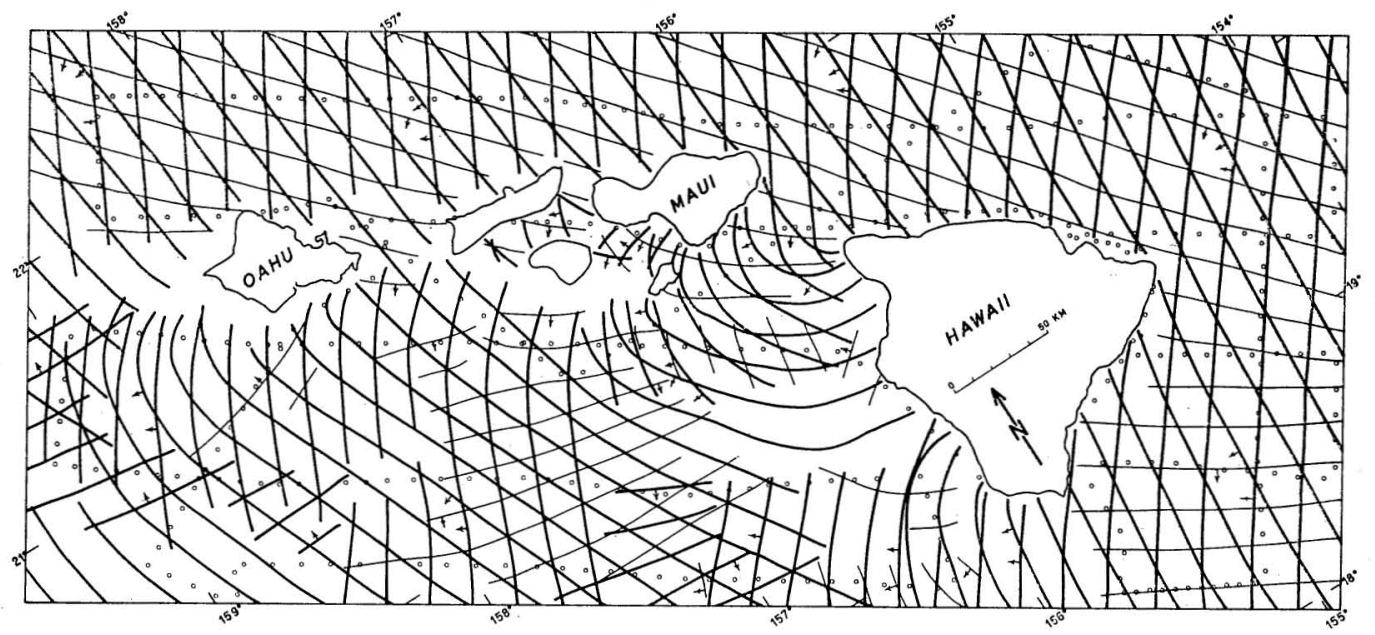

FIG. 3. Wave pattern based upon aerial observation at positions indicated by circles on 31 August and 1 September 1961. The wide lines show changing directions of crest lines of each of three different trains of 7-sec waves. The narrow lines show the same for several trains of short-period (about 1-sec) waves.

this material has been deposited to form sandy shores chiefly in the immediate lee of prominent rocky headlands where the intensity of wave attack and of longshore currents is sharply reduced. Generally this lee is west of headlands, but on Lanai it is on the east side because that side is sheltered by nearby Maui. Muddy shores are not common, but those which do exist are in areas which have the greatest protection from waves, well into the lee of the islands or of headlands.

In recent years there has been erosion of certain sand beaches, particularly those on the east side of Kauai, the north side of Oahu, and the north side of Maui. In part, this erosion has probably resulted from man's activities. However, the close relationship between shore type and degree of exposure exhibited by Figure 4 suggests another cause. As shown by Wentworth (1949), there may have been a directional change of trade winds at Honolulu from a mean of $050^{\circ}$ in 1908 to $085^{\circ}$ between 1925 and 1939 to $063^{\circ}$ in 1943 . If the trend is real and if it continued into recent years, the average wind direction would again have been about $050^{\circ}$ sometime between 1950 and 1960. Although the wind direction at Honolulu may not correspond exactly with the direction of the winds at sea because of the deflecting effects of nearby mountains, the changes in wind direction at Honolulu may well reflect changes at sea. Such a change of wind direction at sea would have produced a corresponding change of wave approach. Possibly the beaches are being shifted somewhat as weather vanes in response to this change in direction of wave approach.

\section{SUMMARY AND CONCLUSIONS}

Mapping of surface winds and wave patterns from the air is a simple procedure. A 2-day survey in the Hawaiian Islands showed that the wind was from the east, but was subject to

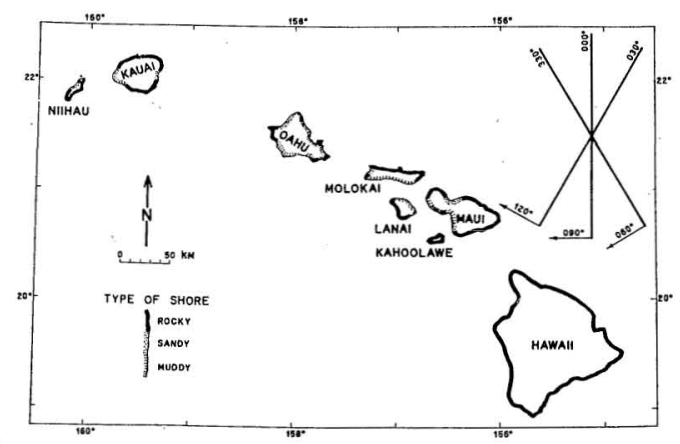

FIG. 4. Relationship of type of shore to degree of exposure to dominant waves. Radiating lines at upper right-hand corner show common azimuths of wave crests and directions of wave approach. 
local deflection by the islands. It was probably typical of the trade-wind period of the year, May through September, when the winds blow from the northeasterly quadrant $80-95 \%$ of the time. From October through April the trade winds still blow from the same general direction most $(65-80 \%)$ of the time (Blumenstock. 1961). The wave pattern was more complex than anticipated, with three trains of 7-sec waves and several trains of about 1 -sec period. Most of the wave energy was in two trains coming from the east and southeast, evidently produced by the trade winds, and agreeing well with the general observation of predominant waves from the east in the Hawaiian region. Shore types of the islands appear to be closely related to degree of exposure to these waves. Rocky shores are generally in the most exposed sectors, sandy shores are in the immediate lee of prominent headlands, and muddy shores are in the most protected sectors. Recent changes of sandy shores may be due to possible long-term changes in the trade winds, with attendant changes in the waves produced by them.

\section{REFERENCES}

ARTHUR, R. S. 1948. Forecasting Hawaiian swell from January 2 to 5, 1947. Bull. Amer. Meteorological Soc. 29:395-400.

1951. The effect of islands on surface waves. Bull. Scripps Inst. Oceanogr. 6: 1-26.
Blumenstock, D. I. 1961. Climate of Hawaii. U.S. Dept. of Commerce, Weather Bur. Climatography U.S. 60-51:1-20.

Bowditch, N. 1943. American practical navigator. U.S. Navy Hydrogr. Off. 9:1-387.

DiETZ, R. S., and E. C. LAFond. 1950. Natural slicks on the ocean. J. Mar. Res. 9:69-76.

EMERY, K. O. 1958. Wave patterns off southern California. J. Mar. Res. 17:133-140.

and D. C. Cox. 1956. Beachrock in the Hawaiian Islands. Pacif. Sci. 10:382-402.

, J. I. TRACEY, JR., and H. S. LADD. 1954. Geology of Bikini and nearby atolls. U.S. Geol. Survey Prof. Pap. 260-A:1-265.

EwING, G. 1950. Slicks, surface films and internal waves. J. Mar. Res. 9:161-187.

LAFOND, E. C. 1959. Slicks and temperature structure in the sea. U.S. Navy Electronics Lab., San Diego Res. Rept. 937: 1-35.

MUNK, W. H. 1947. A critical wind speed for air-sea boundary processes. J. Mar. Res. 6: 69-76.

SHEPARD, F. P., G. A. MACDONALD, and D. C. Cox. 1950. The tsunami of April 1, 1956. Bull. Scripps Inst. Oceanogr. 5:391-528.

WENTWORTH, C. K. 1949. Directional shift of trade winds at Honolulu. Pacif. Sci. 3:86-88.

WoODCOCK, A. H. 1944. A theory of surface water motion deduced from the wind-induced motion of the Physalia. J. Mar. Res. 5: 196-205. 